\title{
Facile synthesis of allyl resinate monomer in an aqueous solution under microwave irradiation
}

\author{
YANJU LU ${ }^{\mathrm{a}, \mathrm{b}}$, MIXIA WANG ${ }^{\mathrm{a}}, \mathrm{ZHENDONG} \mathrm{ZHAO}^{\mathrm{a}, \mathrm{b}, *}$, YUXIANG CHEN ${ }^{\mathrm{a}, \mathrm{b}}$, \\ SHICHAO XU ${ }^{\mathrm{a}}$, JING WANG ${ }^{\mathrm{a}, \mathrm{b}}$ and LIANGWU BI ${ }^{\mathrm{a}, \mathrm{b}}$ \\ ${ }^{a}$ Institute of Chemical Industry of Forest Products, CAF; National Engineering Laboratory for Biomass \\ Chemical Utilization; Key and Open Laboratory on Forest Chemical Engineering, SFA; Key Laboratory of \\ Biomass Energy and Material, Jiangsu Province, Nanjing 210042, China \\ ${ }^{b}$ Research Institute of Forestry New Technology, CAF, Beijing 100091, China \\ e-mail: zdzhao@189.cn; luyanju-1982@163.com
}

MS received 26 November 2014; revised 5 March 2015; accepted 8 March 2015

\begin{abstract}
We have developed a facile method for production of allyl resinate monomer (allyl rosin ester) via a phase transfer reaction under microwave irradiation. The synthesis of allyl resinate was conducted using allyl chloride and sodium resinate as starting materials in aqueous solution at $50^{\circ} \mathrm{C}$ for $30 \mathrm{~min}$ with a yield of $94.7 \%$, which is $20 \%$ higher than conventional heating method. The products precipitated spontaneously from the aqueous phase after reaction, which significantly facilitated the subsequent separation of monomer products. The synthesized monomer product appeared as a viscous liquid, with a viscosity of $460 \mathrm{mPa} \cdot \mathrm{s}$ at $25^{\circ} \mathrm{C}$ and a density of $1.0469 \mathrm{~g} / \mathrm{cm}^{3}$. The physical and chemical properties suggested that the synthesized monomer has great potential for free radical polymerization.
\end{abstract}

Keywords. Allyl resinate; microwave energy; rosin-derivatives; phase transfer catalysis

\section{Introduction}

In recent years, there has been an increasing interest in the synthesis of environmental protection chemicals using renewable resources such as rosin. Fossil resources can be substituted by renewable resources in the synthesis of many chemicals. ${ }^{1}$ Rosin is a plentiful and cheap renewable resource mainly composed of diterpene resin acids and related molecules. China is the largest exporter of rosin in the world. The utilization of rosin brings benefits to the sustainable development of the Chinese chemical industry.

Nowadays, rosin has been widely used in industry in various forms. Rosin ester is one of the most important rosin derivative products and has been applied extensively due to its excellent properties. However, unlike common carboxylic acids, the carboxyl group of resin acid is positioned on a tertiary carbon atom, which makes the esterification more difficult, with heating up to $180-290^{\circ} \mathrm{C}$ for $10-20 \mathrm{~h}$ which is often required. ${ }^{2-4}$ Consequently, many undesired by-products are generated under high reaction temperature, which reduces the yield of the final product. This problem became worse when those thermosensitive groups such as double bond

\footnotetext{
*For correspondence
}

introduced into the rosin structure. In addition, complicated separation processes are needed for product purification.

Several researchers have tried to introduce the rosin structure into functional polymers. Kim W S et al. ${ }^{5}$ provided a method to synthesize poly (vinylbenzyl abietate) using poly(vinylbenzyl chloride) and sodium abietate as raw materials. Kim $\mathrm{T} \mathrm{H}$ et al. ${ }^{6}$ reported the synthesis of polymethacrylate upon the reaction of poly(glycidyl methacrylate) with abietic acid. In these two methodologies, resin derivatives were not used as monomers in the polymerization. In other words, directly introducing rosin structure into the polymer is a demanding research. These polymers were based on the polymerization of other kinds of monomers besides resin derivatives. The main reason for this is that the unsaturated groups such as a vinyl group tends to polymerize at high temperatures during the esterification reaction of rosin acids and allyl alcohol. Therefore, it is important to find a mild or facile reaction pathway to form a monomer product with a combination of the molecular structure of rosin and unsaturated groups.

In our previous work, the synthesis of allyl resinates using $\mathrm{N}, \mathrm{N}$-dimethyl formamide (DMF) as solvent through phase-transfer catalysis was investigated., ${ }^{7,8}$ The yield of the product was up to $70 \%$ with a purity 
of $90 \%$ under a reaction temperature of $50^{\circ} \mathrm{C}$. The monomer product showed excellent reactivity during radical polymerization. However, the reaction time was long, usually taking over $7 \mathrm{~h}$ to complete the reaction. The use of DMF as an organic solvent also comes with concerns, such as expenditure, recycling and recovery, as well as environmental issues.

In 1986, Gedye ${ }^{9}$ discovered that the reaction rate of the SN2 nucleophilic substitution of 4-cyano benzene oxygen ions and benzyl chloride could be improved 1240 times with higher yields by microwave irradiation. Since then, microwave assisted organic chemical reactions have been more favoured by chemical industries, forming a high-profile area as a consequence. ${ }^{10}$ In this study, a new method to synthesize allyl resinates monomer is proposed: using water as the solvent under microwave irradiation. We believe that the phase transfer reaction could be promoted efficiently with microwave irradiation. The successful replacement of petrochemical solvents with water in this reaction has the potential to reduce the production cost of monomers. The effects of microwave power, reaction time, molar ratio, catalyst amount and reaction temperature on the yield, and the component distribution of the products were studied. The synthesized product was characterized by GC, GCMS and FT-IR spectroscopy. The physical and chemical properties of the allyl resinate product were also investigated.

\section{Experimental}

\subsection{Chemicals}

Pinus elliottii rosin for this study was from a commercially purchased board, which was produced in Taihe, Jiangxi province, China. The main properties of Pinus elliottii rosin are given in table 1. All the other reagents used in this work were of analytical grade.

Table 1. Physical and chemical properties of Pinus elliottii rosin.

\begin{tabular}{lc}
\hline Properties & Observed value \\
\hline Colour & Yellow \\
Softening point (ring \& ball) $\left({ }^{\circ} \mathrm{C}\right)$ & 75.2 \\
Alcohol-insoluble residue $(\%)$ & 0.04 \\
Unsaponifiable matter $(\%)$ & 3.78 \\
Ash $(\%)$ & 0.03 \\
Acid value $(\mathrm{mg} / \mathrm{g})$ & 168 \\
\hline
\end{tabular}

\subsection{Synthesis of allyl resinate under microwave energy}

2.2a Purification of rosin acids: Rosin (20 g) was dissolved in $15 \mathrm{~mL}$ of acetone in a three-necked flask and stirred at $60^{\circ} \mathrm{C}$ for $10 \mathrm{~min}$. After complete dissolution, the mixture was cooled to room temperature to obtain the crystallized product. The obtained solid was filtered and recrystallized twice in acetone. After purification, the total yield of the product was approximately $35 \%$ with an acid value of $184.6 \mathrm{mg} / \mathrm{g}(185.5 \mathrm{mg} / \mathrm{g}$ by theory), whose purity was predicted as $99.5 \%$ as resin acids.

2.2b Synthesis of allyl resinate: In a typical operation, the reaction was carried out in a MAS-II atmospheric pressure microwave synthesis/extraction reaction workstation (Shanghai Sineo Microwave Chemical Technology Co. Ltd.) equipped with a $250 \mathrm{~mL}$ glass reaction vessel and an internal temperature sensor. The reaction pathway is shown in scheme 1 (allyl abietate is a representative compound of allyl resinate).

Sodium hydroxide $(1.4 \mathrm{~g})$ was dissolved in $10 \mathrm{~mL}$ of water, which was then added dropwise to rosin acids $(10.0 \mathrm{~g}, 0.033 \mathrm{~mol})$ in $20 \mathrm{~mL}$ of water. The mixture was stirred at room temperature for $1 \mathrm{~h}$, and then used in the next step without any further manipulation. The mixture of sodium resinate $(10.7 \mathrm{~g}, 0.033 \mathrm{~mol})$ and allyl chloride $(2.5 \mathrm{~g}, 0.033 \mathrm{~mol})$, including a trace of $p$-benzoquinone as a polymerization inhibitor and hexadecyltrimethylammonium bromide as a phase-transfer catalyst (CTAB), was heated under microwave irradiation at $300-700 \mathrm{~W}, 40-65^{\circ} \mathrm{C}$ for $15-35 \mathrm{~min}$. After that, the monomer products were precipitated and separated from the aqueous solution using a funnel, from which the unreacted allyl chloride was recovered by distillation.

2.2c Analysis methods: Gas chromatography (GC) was carried out using a Shimadzu GC2014AF, equipped with a RTX-5 quartz capillary column (length 30.0 $\mathrm{m}$, inner diameter $0.25 \mathrm{~mm}$, film thickness $0.25 \mu \mathrm{m}$, injection volume $2.0 \mu \mathrm{L}$ ). The column was held at $100^{\circ} \mathrm{C}$ for $2 \mathrm{~min}$, and then heated to $180^{\circ} \mathrm{C}$ at a rate of $4^{\circ} \mathrm{C} / \mathrm{min}$. Then the temperature was further increased to $270^{\circ} \mathrm{C}$ at a rate of $2^{\circ} \mathrm{C} / \mathrm{min}$ for $10 \mathrm{~min}$. The general gas chromatography-mass spectrometry (GC-MS) profile for the allyl resinate monomer was obtained on a GC-MS system (Agilent 6890N/5973N) equipped with a HP-5 quartz capillary column (length $30.0 \mathrm{~m}$, inner diameter $0.25 \mathrm{~mm}$, film thickness $0.25 \mu \mathrm{m}$, injection volume $2.0 \mu \mathrm{L}$ ). The test conditions of GC-MS are the 


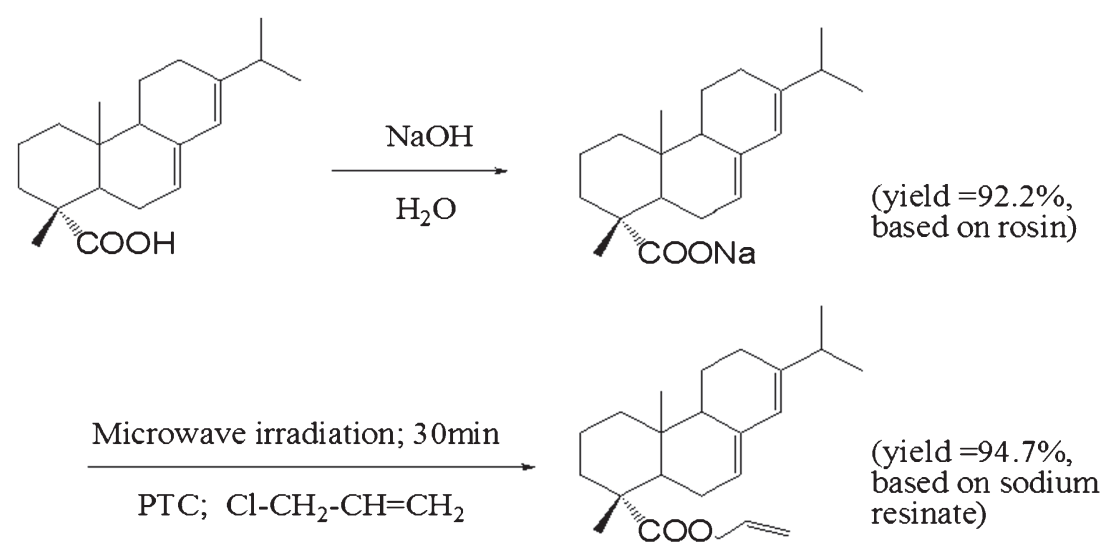

Scheme 1. Synthesis of allyl resinate under microwave irradiation (allyl abietate is a representative compound of rosin).

same as the GC conditions. The identification of the components of the products was confirmed using total ion chromatograms as well as the fragmentation pattern.

Fourier transform infrared (FT-IR) spectroscopic analysis of the rosin material and the synthesized allyl resinate was performed on a Thermo Nicolet FT-IR Spectrometer (Nexus 670, resolution: $32 \mathrm{~cm}^{-1}$, scan: 64 times, range: $4000-600 \mathrm{~cm}^{-1}$, thin film, $25^{\circ} \mathrm{C}$ ).

The acid number was measured according to the China National Standard method GB/T 8146-2003. Viscosity was measured using a Cole Parmer (Vernon Hills, IL) 98936 series viscosity centipoises according to the Chinese standard test method GB/T 15357-1994.

\section{Results and Discussion}

\subsection{Effect of microwave energy on the promotion of the reaction}

Figure 1 shows the results of the phase transfer reaction in different solvents with conventional and microwave assisted heating. The corresponding results in regard to product yield and purity were also investigated. It can be seen that water has little effect on the reaction using conventional heating. The reactant mixture remains a uniform clear solution after reaction and a few allyl resinate derivatives were detected. On the other hand, a high yield of product was obtained using DMF as an organic solvent. The product was obtained in a yield of $70 \%$ with a purity of $93 \%$. This result indicates that the combination of organic solvent and phase transfer catalyst plays an important role in providing a homogeneous environment for the reactants (sodium resinate and allyl chloride), which is beneficial to the formation of the allyl resinate product. Furthermore, the reaction using DMF as an organic solvent under microwave irradiation was carried out. It was found that the yield of product was promoted significantly to $90 \%$ with a

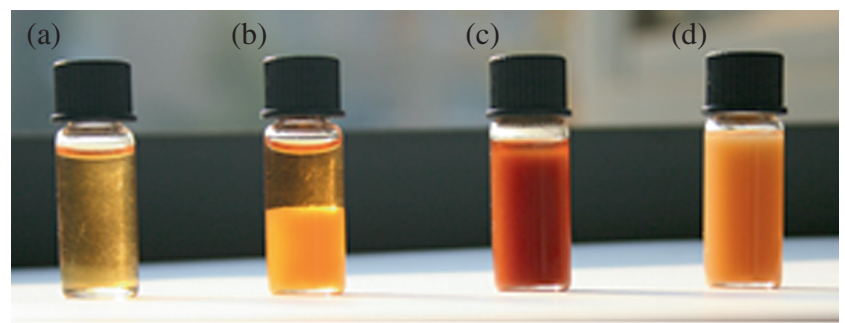

Figure 1. Results of reaction in different solvents with conventional heating and microwave irradiation. (All reactions were carried out using $n$ (sodium resinate) $/ n$ (allyl chloride) $=1: 2$ at $50^{\circ} \mathrm{C}$. (a) Solvent: water, reaction time $7 \mathrm{~h}$, conventional heating; (b) solvent: water, reaction time 30 min, microwave power $300 \mathrm{~W}$, microwave heating; (c) solvent: DMF, reaction time $7 \mathrm{~h}$, conventional heating; (d) solvent: DMF, reaction time $30 \mathrm{~min}$, microwave power $300 \mathrm{~W}$, microwave heating).

reaction time of $30 \mathrm{~min}$. However, the use of DMF as an organic solvent could result in some problems, such as the high cost of the solvent and recycling the solvent from the products, as well as some environmental concerns.

As a result, we investigated the use of water as the solvent under microwave irradiation. The corresponding results regarding product yield and purity can be found in figure 2. The result showed that the reaction could be completely finished in no more than $30 \mathrm{~min}$ using water as the reaction solvent. After reaction, the products can be easily obtained by spontaneous precipitation from the reaction mixture. It was found that the yield of the product was promoted significantly from approximately $70 \%$ to $90 \%$ under microwave irradiation. As is well known, water is the cheapest, most abundant and non-toxic solvent. Moreover, we believe that the use of microwave irradiation offers the advantage of very rapid heating throughout the volume of the reaction mixture, which has the effect of speeding up the reaction when compared to reactions using 


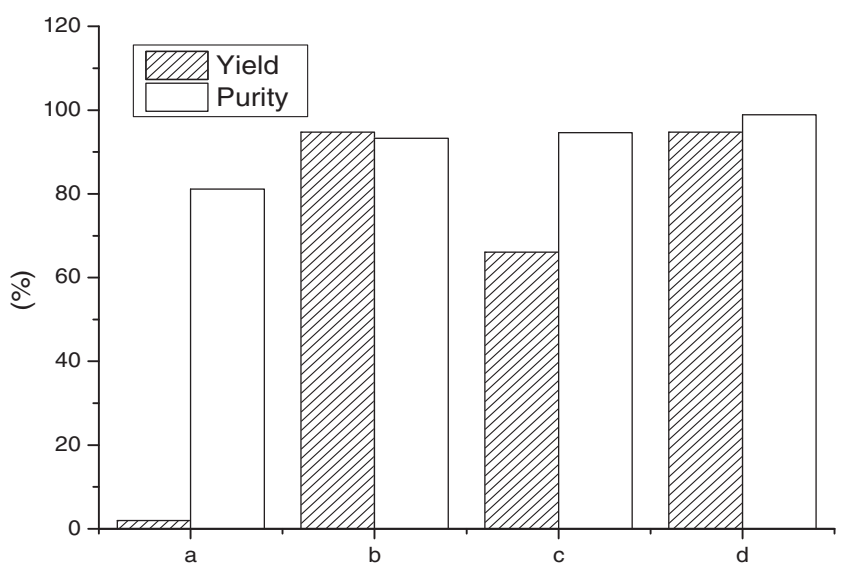

Figure 2. Yield and purity of the products at different reaction conditions. (a). solvent: water, reaction time $7 \mathrm{~h}$, conventional heating; (b) solvent: water, reaction time $30 \mathrm{~min}$, microwave power $300 \mathrm{~W}$, microwave heating; (c) solvent: DMF, reaction time $7 \mathrm{~h}$, conventional heating; (d) solvent: DMF, reaction time $30 \mathrm{~min}$, microwave power $300 \mathrm{~W}$, microwave heating).

conventional heating methods. ${ }^{11-13}$ The reaction speed was also accelerated up to approximately 15 times when compared with conventional heating. Therefore, a new method for producing allyl resinate derivatives was proposed by the introduction of microwave irradiation during the reaction.

\subsection{Effect of reaction parameters on the phase transfer catalytic reaction}

Different parameters on the yield of products were investigated and the results are also shown in table 2. The reaction conditions of microwave power on the reaction results were as follows: the ratio of allyl chloride and sodium rosin was 1:1 (molar ratio, the same as follows), the amount of CTAB 5\% (mass fraction of sodium rosinate), trace $p$-benzoquinone as a polymerization inhibitor, a reaction temperature of $50^{\circ} \mathrm{C}$ and reaction time $30 \mathrm{~min}$.

As shown in table 2, microwave power had significant effects on the yields of allyl resinate. The yield of the product increased with the increase of microwave power from 300 to $500 \mathrm{~W}$. The enhancement of the electromagnetic power promotes the frequency of the collisions of reactants during the reaction. However, it was found that undesired products were observed due to the side reactions when the microwave power is over 400 W. Therefore, suitable reaction power is $400 \mathrm{~W}$.

The effect of reaction time on the yield of allyl resinate was also investigated. The results showed that the minimum yield of allyl resinate was observed when the reaction time was $15 \mathrm{~min}$. The yield of allyl resinate
Table 2. Yield of allyl resinate at different reaction conditions.

\begin{tabular}{lcc}
\hline Items & $\begin{array}{c}\text { Reaction } \\
\text { conditions }\end{array}$ & $\begin{array}{c}\text { Yield } \\
(\%)\end{array}$ \\
\hline Microwave power(W) & 300 & 77.7 \\
& 400 & 94.7 \\
& 500 & 90.9 \\
Reaction time(min) & 600 & 87.1 \\
& 700 & 87.1 \\
& 15 & 43.6 \\
Reaction temperature $\left({ }^{\circ} \mathrm{C}\right)$ & 20 & 70.1 \\
& 25 & 77.7 \\
& 30 & 81.4 \\
& 35 & 85.2 \\
& 40 & 7.6 \\
Amount of catalyst $(\%)$ & 45 & 81.1 \\
& 50 & 89.0 \\
& 55 & 85.2 \\
& 60 & 81.1 \\
& 1 & 70.1 \\
& 1.5 & 77.7 \\
& 2 & 81.4 \\
& 2.5 & 85.2 \\
& 3 & 73.9 \\
& 1 & 53.0 \\
& 2 & 70.1 \\
& 3 & 72.0 \\
& 4 & 90.9 \\
& 5 & 92.8 \\
\hline
\end{tabular}

was increased with an incremental increase in reaction time from 15 to $30 \mathrm{~min}$, and the highest yield was obtained when the reaction time was $30 \mathrm{~min}$. However, the results showed that the yield and purity decreased because of the secondary reactions after $30 \mathrm{~min}$.

The reaction temperature has a close relationship with the yield of product. The reaction failed almost totally when the temperature was below $40^{\circ} \mathrm{C}$. Only $7.6 \%$ of the product was obtained at the temperature of $40^{\circ} \mathrm{C}$. However, the yield of product dramatically increased to $81.1 \%$ at the temperature of $45^{\circ} \mathrm{C}$. Further increasing the reaction temperature did not help with the increment of the product yield. This result indicated that this reaction has a critical temperature at $45^{\circ} \mathrm{C}$, which is closely related to the boiling point of allyl chloride $\left(44.6^{\circ} \mathrm{C}\right)$. By consideration of the product yield and the side reactions, the optimum reaction temperature was $50^{\circ} \mathrm{C}$.

The molar ratio of allyl chloride and sodium resinate was also observed as an important factor for product yield. We can see that a slight increase in yield was observed at lower ratios of allyl chloride to sodium resinate $(<1.5)$, and a rapid increase in yield was observed when the molar ratio increased to 2 . Under 
Table 3. GC content of allyl resinate.

\begin{tabular}{lccc}
\hline Peak number & Retention time $(\mathrm{min})$ & Component & GC content $(\%)$ \\
\hline 1 & 43.9 & Allyl pimarate & 0.2 \\
2 & 44.6 & Allyl sandaracopimarate & 0.1 \\
3 & 46.0 & Allyl isopimarate & 12.0 \\
4 & 46.5 & Allyl palustriate & 6.0 \\
5 & 46.9 & Allyl 7,15-pimarate & 0.5 \\
6 & 47.7 & Allyl dehydroabietate & 5.2 \\
7 & 49.9 & Allyl abietate & 67.9 \\
8 & 51.8 & Allyl neoabietate & 0.7 \\
Others & - & Unidentified allyl esters & 7.4 \\
\hline
\end{tabular}

a molar ratio of $n$ (allyl chloride) $/ n$ (sodium resinate) $=2.5: 1$, the maximum yield of allyl resinate was observed, which is $85.2 \%$. However, the yield was decreased significantly when the ratio increased from 2.5 to 3 . The yield of allyl resinate was initially increased then decreased with an increase in the amount of catalyst used, but there was little difference between the use of $4 \%$ and $5 \%$ catalyst, so the optimum catalyst amount was $4 \%$.

In summary, the optimum reaction conditions are as follows: microwave power $400 \mathrm{~W}$, reaction time $30 \mathrm{~min}$, catalyst amount $4 \%$, reaction temperature $50^{\circ} \mathrm{C}, n$ (allyl chloride) $/ n$ (sodium resinate) $2.5: 1$. Under these optimum conditions, the yield of allyl resinate is $94.7 \%$, in which total content of allyl resinate was $92.6 \%$ and other unidentified allyl esters was $7.4 \%$. Additional experiments were repeated thrice to confirm the reliability of the results.

\subsection{Physical properties and chemical analysis of the allyl resinate monomer}

The product was analyzed by GC and the list of compounds given in table 3. Allyl resinates were abundant including allyl pimarate, allyl sandaracopimarate, allyl isopimarate, allyl palustriate, allyl 7,15-pimarate, allyl dehydroabietate, allyl abietate and allyl neoabietate, etc. Allyl abietate is typically the most abundant allyl resinate in the monomer product, accounting for more than $67.9 \%$ of the total area of all peaks. The total content of allyl resinates was $92.6 \%$, and the total content of other unidentified allyl esters was $7.4 \%$.

Due to the high purity of the allyl resinate, we believe the synthesized monomer has high potential to be used as oligomer products such as inks and coatings. Compared with the oligomer from fossil resources such as acrylic resins and styrene resins, we believe the introduction of the resin structure into polymer products can provide specific mechanical properties, such as hardness and flexibility.

$\mathrm{GC}$ analysis of each component in the allyl resinate monomer is shown in table 3. GC-MS spectra were used to identify the compounds that eluted in each chromatographic peak. The ions in the GC-MS spectra that can be assigned to the derivatives of resin acids are listed in table 3. These assignments were made on the basis of the scheme shown in figure 3.

Taking allyl abietate as an example, it can be seen from the GC-MS analysis that $m / z 343$ is the $\mathrm{M}+1$ peak. The $m / z 342$ fragment ion is the molecular ion

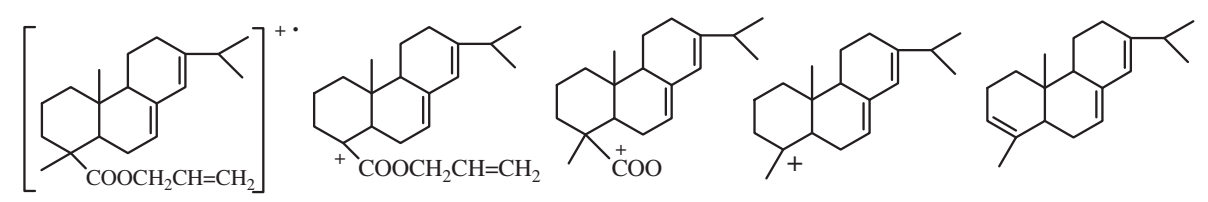

$m / z=342 \quad m / z=327 \quad m / z=301 \quad m / z=257 \quad m / z=256$

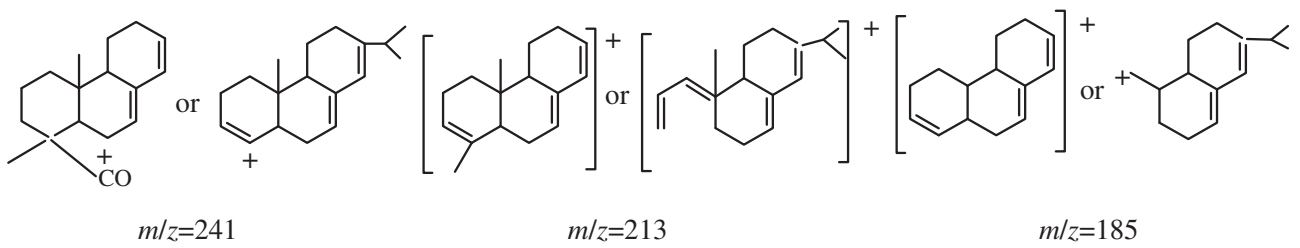

Figure 3. Possible structures of fragment ions of allyl resinate. 
Table 4. Identification of allyl resinate by GC-MS.

\begin{tabular}{|c|c|c|}
\hline Identified compound & $R_{\mathrm{t}}(\min )$ & Fragments and their intensity \\
\hline Allyl pimarate & 43.9 & $\begin{array}{c}343(\mathrm{M}+1,3), 342\left(\mathrm{M}^{+\cdot}, 12\right), \\
327\left(\mathrm{M}-\mathrm{CH}_{3}, 8\right), 257\left(\mathrm{M}-\mathrm{COOC}_{3} \mathrm{H}_{5}, 22\right), \\
\left.241\left(\mathrm{M}-\mathrm{HCOOC}_{3} \mathrm{H}_{5}-\mathrm{CH}_{3} \text { or } \mathrm{M}_{-}-\mathrm{OC}_{3} \mathrm{H}_{5}-\mathrm{C}_{3} \mathrm{H}_{7}, 11\right),\right) \\
206\left(\mathrm{M}-\mathrm{HCOOC}_{3} \mathrm{H}_{5}-\mathrm{CH}_{3}-\mathrm{C}_{2} \mathrm{H}_{4}-7 \mathrm{H}, 14\right), \\
161\left(\mathrm{M}-\mathrm{C}_{5} \mathrm{H}_{10}-\mathrm{COOC}_{3} \mathrm{H}_{5}-\mathrm{C}_{2} \mathrm{H}_{2}\right. \\
9), 121\left(\mathrm{C}_{9} \mathrm{H}_{13}, 100\right)\end{array}$ \\
\hline Allyl sandaracopimarate & 44.6 & $\begin{array}{c}343(\mathrm{M}+1,4), 342\left(\mathrm{M}^{+\cdot}, 17\right), \\
327\left(\mathrm{M}-\mathrm{CH}_{3}, 15\right), 257\left(\mathrm{M}-\mathrm{COOC}_{3} \mathrm{H}_{5}, 19\right), \\
241\left(\mathrm{M}-\mathrm{COOC}_{3} \mathrm{H}_{5}-\mathrm{CH}_{3} \text { or } \mathrm{M}_{-} \mathrm{OC}_{3} \mathrm{H}_{5}-\mathrm{C}_{3} \mathrm{H}_{7},\right. \\
13), 207\left(\mathrm{M}-\mathrm{HCOOC}_{3} \mathrm{H}_{5}-\mathrm{CH}_{3}-\mathrm{C}_{2} \mathrm{H}_{4}-6 \mathrm{H}, 12\right), \\
133\left(\mathrm{M}-\mathrm{C}_{5} \mathrm{H}_{10}-\mathrm{COOC}_{3} \mathrm{H}_{5}-\mathrm{C}_{4} \mathrm{H}_{6},\right. \\
15), 121\left(\mathrm{C}_{9} \mathrm{H}_{13}, 100\right)\end{array}$ \\
\hline Allyl isopimarate & 46.0 & $\begin{array}{c}343(\mathrm{M}+1,5), 342\left(\mathrm{M}^{+\cdot},\right. \\
18), 327\left(\mathrm{M}-\mathrm{CH}_{3}, 7\right), 313\left(\mathrm{M}-2 \mathrm{CH}_{3}, 9\right), \\
301\left(\mathrm{M}-\mathrm{C}_{3} \mathrm{H}_{5}, 31\right), 256\left(\mathrm{M}-\mathrm{HCOOC} \mathrm{H}_{5},\right. \\
70), 255\left(\mathrm{M}-\mathrm{HCOOC} \mathrm{H}_{5}-\mathrm{H}, 34\right), \\
241\left(\mathrm{M}-\mathrm{CH}_{3}-\mathrm{HCOOC}_{3} \mathrm{H}_{5} \text { or }\right. \\
\left.\mathrm{M}-\mathrm{OC}_{3} \mathrm{H}_{5}-\mathrm{C}_{3} \mathrm{H}_{7}, 100\right)\end{array}$ \\
\hline Allyl palustriate & 46.5 & 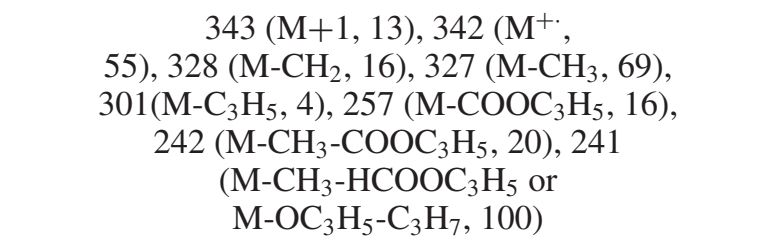 \\
\hline Allyl dehydroabietate & 47.7 & $\begin{array}{c}341(\mathrm{M}+1,3), 340\left(\mathrm{M}^{+} \cdot\right. \\
12), 325\left(\mathrm{M}-\mathrm{CH}_{3}, 10\right), 255\left(\mathrm{M}-\mathrm{COOC}_{3} \mathrm{H}_{5}, 4\right), \\
240\left(\mathrm{M}-\mathrm{CH}_{3}-\mathrm{COOC}_{3} \mathrm{H}_{5} \text { or } \mathrm{M}-\mathrm{OC}_{3} \mathrm{H}_{5}-\mathrm{C}_{3} \mathrm{H}_{7},\right. \\
20), 239\left(\mathrm{M}-\mathrm{CH}_{3}-\mathrm{HCOOC} \mathrm{H}_{5}, 100\right), \\
197\left(\mathrm{C}_{15} \mathrm{H}_{17}, 4\right), 141\left(\mathrm{C}_{11} \mathrm{H}_{9}, 5\right)\end{array}$ \\
\hline Allyl 7,15-pimarate & 46.9 & 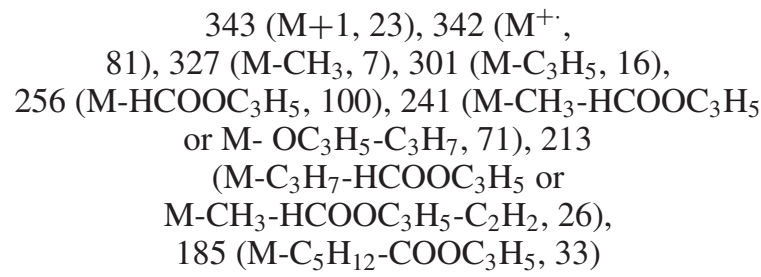 \\
\hline Allyl abietate & 49.9 & 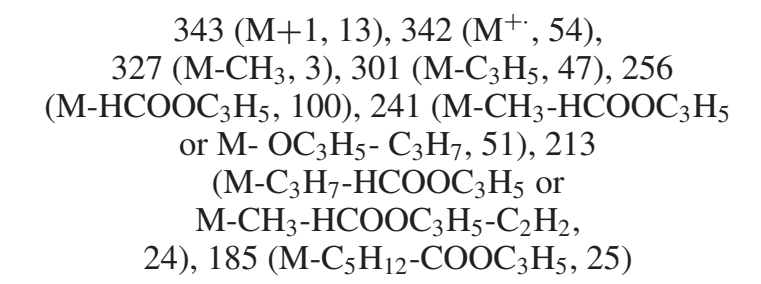 \\
\hline Allyl neoabietate & 51.8 & $\begin{array}{c}343(\mathrm{M}+1,9), 342\left(\mathrm{M}^{+}, 38\right), \\
149\left(\mathrm{C}_{11} \mathrm{H}_{17}, 5\right), 148\left(\mathrm{M}-\mathrm{C}_{8} \mathrm{H}_{11}-\mathrm{COOC}_{3} \mathrm{H}_{5},\right. \\
26), 136\left(\mathrm{C}_{10} \mathrm{H}_{16}, 16\right), 135\left(\mathrm{C}_{10} \mathrm{H}_{15}, 100\right), \\
134\left(\mathrm{M}-\left(\mathrm{CH}_{3}\right)_{4}-\mathrm{C}_{5} \mathrm{H}_{5}-\mathrm{COOC}_{3} \mathrm{H}_{5}, 15\right), \\
121\left(\mathrm{C}_{9} \mathrm{H}_{13}, 28\right)\end{array}$ \\
\hline
\end{tabular}


(a)

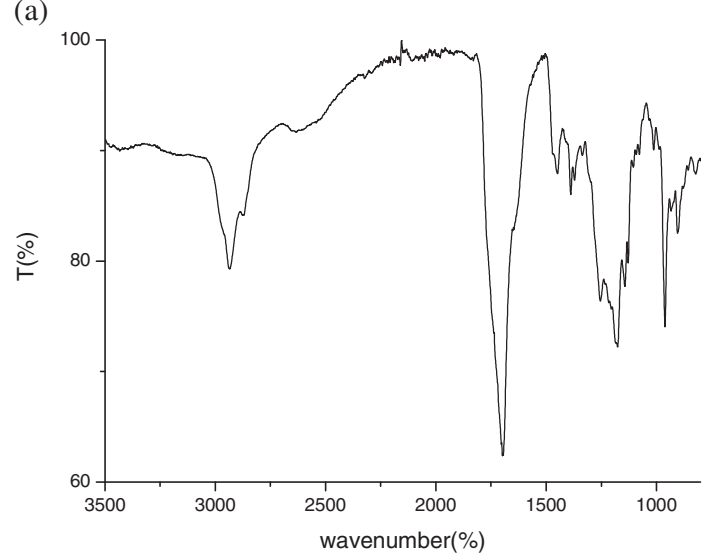

(b)

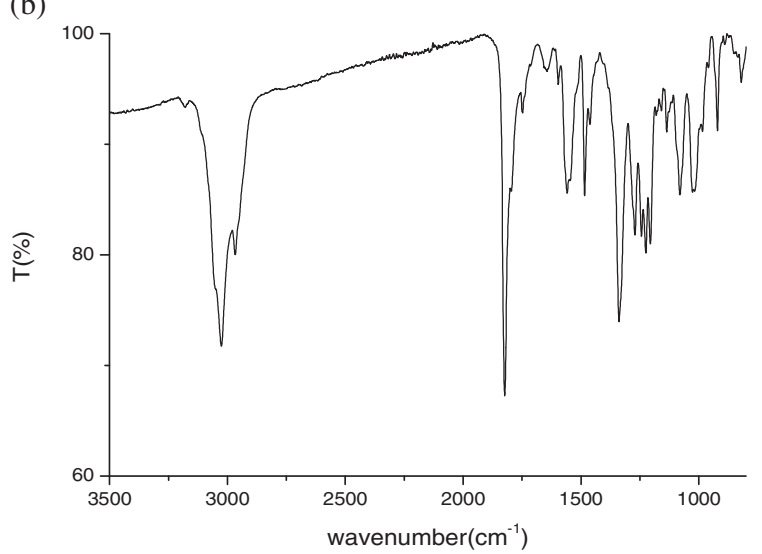

Figure 4. FT-IR spectra of rosin (a) and allyl resinate (b).

peak. $m / z 327$ may be the demethylated fragment ion. $\mathrm{m} / \mathrm{z}, 301$ may be the deallylated fragment ion. $\mathrm{m} / \mathrm{z} 256$ is the base peak, which may be the decarboxylated and deallylated fragment ion and reduced by a proton, and the removed ion form of allyl formate. $m / z 241$ may be the fragment ion peak reduced by a carboxyl, allyl and methyl; or the fragment ion peak reduced by a allyl, isopropyl and an oxygen, usually isopropyl will be removed more easily than methyl after the ester ion is removed, which forms propylene. $m / z 213$ may be the fragment ion reduced by a carboxyl, allyl, methyl and vinyl, and a partially removed ion form of allyl formate; or fragment ion peak reduced by a carboxyl, allyl, isopropyl. $m / z 185$ may be a fragment ion reduced by a carboxyl, allyl, isopropyl and methyl; or a fragment ion peak reduced by a carboxyl, allyl, methyl and vinyl. Analysis of other ions of allyl resinate are shown in table 4.

The FT-IR spectra of the rosin and allyl resinate monomer are identified and the spectra of rosin and allyl resinate were shown in figure 4 . The sample underwent significant changes between rosin and allyl resinate, as revealed by the appearance of the peak $\left(v_{\max }\right.$ $\mathrm{cm}^{-1}$ ) at 1723 corresponding to the ester group, 1648 is the stretching vibration of $\mathrm{C}=\mathrm{C}$, and 3078 is the stretching vibration of $=\mathrm{C}-\mathrm{H}$. The spectrum of the synthesized allyl resinate displays the distinctive bands of the allyl group. The intensities of the transmission bands at

Table 5. The physical appearance of allyl resinate.

\begin{tabular}{lc}
\hline Physical appearance & Measured value \\
\hline Appearance & Pale yellow, transparent \\
Viscosity $\left(\mathrm{mPa} \cdot \mathrm{s}, 25^{\circ} \mathrm{C}\right)$ & 460 \\
Refractive index $\left(25^{\circ} \mathrm{C}\right)$ & 1.5274 \\
Density $\left(\mathrm{kg} / \mathrm{m}^{3}, 25^{\circ} \mathrm{C}\right)$ & $1.0469 \times 10^{3}$ \\
Acid value $(\mathrm{mg} / \mathrm{g})$ & 1.84 \\
\hline
\end{tabular}

2925 and 2867 are related to $\mathrm{CH}_{2}$ and $\mathrm{CH}_{3}$ chain formation. Peaks related to $\mathrm{C}=\mathrm{C}$ and $\mathrm{C}=\mathrm{O}$ at 1648 and 1723 , respectively, were observed in the spectrum of the allyl resinate. It indicated that there is an ester group in the product.

Table 5 shows the physical and chemical properties of the synthesized allyl resinate monomer. The monomer product appeared as a viscous liquid at room temperature, with a viscosity of $460 \mathrm{mPa} \cdot \mathrm{s}$ at $25^{\circ} \mathrm{C}$. The density and the acid value of the monomer were determined as $1.0469 \times 10^{3} \mathrm{~kg} / \mathrm{m}^{3}$ and $1.84 \mathrm{mg} / \mathrm{g}$, respectively. The physical and chemical properties suggested that the synthesized monomer has great potential for free radical polymerization.

\section{Conclusions}

Allyl resinate is proposed as a new type of natural rosinderived reactive monomer. The phase transfer reaction for the monomer production can be significantly accelerated under microwave irradiation. The newly synthesized monomer, consisting of high purity allyl resonate derivatives, is proposed to have plenty of reactive functionalities during free radical polymerization. We believe that the introduction of the rosin structure into polymer structures will show good mechanical properties, especially in intensity and ductility. Further studies are needed on the production of polymer, including their application in inks and coatings, which are currently under investigation in our research group.

\section{Acknowledgements}

This research was supported by the National Nonprofit Institute Research Grant of CAFINT (Grant No. CAFINT2013C01) and the National Natural Science Foundation of China (Grant No. 31370575). 


\section{References}

1. Qin R X, Liang Z Y, Li G Z, Chen H Y and Wen C L 2012 J. Anhui Agric. 4014312

2. Zhang S N, Xie H, Huang L and Ma X S 2009 Therm. Resin 2422

3. Wu L Y, Wang Y M, Meng Q X and Niu Z T 2010 Appl. Chem. Ind. 391564

4. Yoshikazu S, Itsuki T 2000 WO patent 068289

5. Kim W S, Jang H S, Hong K H and Seo K H 2001 Macromol. Rapid Commun. 22825

6. Kim T H, Chang J Y, Choi J U and Kim W S 2005 Macromol. Res. 13545
7. Lu Y J, Zhao Z D, Chen Y X, Gu Y and Bi L W 2009 Chem. Ind. Eng. Prog. 281261

8. Lu Y J, Zhao Z D, Chen Y X and Bi L W 2011 Polym. J. 43869

9. Gedye R, Smith F, Westaway K, Ali H, Baldisera L, Laberge L and Rousell J 1986 Tetrahedron Lett. 27 279

10. Zhao X X 2012 Sci. Tech. Eng. 122475

11. Geoffrey A, Tompsett D and William C C K 2006 Chem. Phys. Chem. 7296

12. Kappe C, Dallinger O and Murp D 2009 In Practical microwave synthesis for organic chemists (Iowa City: The University of Iowa) p. 15

13. Edouard C, Catherine M and Mercier R 2014 Polymer 551 